\title{
Mathematical model for power consumption at mixing of industrial and domestic wastewater sludge
}

\author{
Ancaelena Eliza STERPU*, Claudia Irina KONCSAG Anca Iuliana DUMITRU and Alina-Daniela MIHALCEA \\ Department of Technology and Chemical Engineering, Ovidius University of Constanta, 124 Mamaia Blvd, \\ 900527 Constanta, Romania
}

\begin{abstract}
Physical investigations have been carried out to characterize the power consumption in a laboratory autoclave vessel equipped with an anchor impeller (diameter $\mathrm{d}=0.068 \mathrm{~mm}$ ), without baffles, at 8 speed ratio, from 100 to $800 \mathrm{rpm}$. The laminar flow regime was investigated using sludge proceeding from the treatment of mixed industrial and domestic wastewater, with a view to its subsequent processing: mixing, filtration, dewatering. The mathematical modeling focused on finding an accurate equation linking the Power number $\left(\mathrm{N}_{\mathrm{p}}\right)$ and the Reynolds number $(\mathrm{Re})$ at different levels $(\mathrm{H})$ of sludge in the vessel.

The rheological curves indicate that the sludge have non-Newtonian behaviors which are better described by the Herschel-Buckley model. The models resulted from the $\mathrm{N}_{\mathrm{p}}$ variation versus $\mathrm{Re}$ are power function type $N_{p}=a \cdot \operatorname{Re}^{b}$, where the coefficient a is a linear functions of $\mathrm{H} / \mathrm{d}$ ratio and $\mathrm{b}=-1.016$ have a constant value.
\end{abstract}

Keywords: wastewater sludge, mixing power, anchor impeller, Herschel-Buckley model

\section{Introduction}

During the last decades, the question of water pollution has taken worrying proportion whereas, at the same time, water consumption increased mainly due to the demographic explosion. Industrialized countries now aim at reducing the pollution of water to preserve their water supply.

This latter point particularly implies to optimize the treatment processes of both industrial and domestic wastewater [1]. Since wastewater treatment has been a subject of interest, it has been established that, to optimize the process parameters of wastewater treatment plants, the understanding of the hydrodynamic behavior of sludge flows is of prime importance [2]. It is also well known that suspensions of sludge are non-Newtonian fluids [3].

The sludge studied in this work has a particular composition because it proceeds from two kinds of wastewater: industrial and municipal; these have very different composition: the industrial sludge proceeding form an oil refinery has a high content of hydrocarbons and heavy metals [4] since the municipal sludge has a high content of grease, nitrogen compounds and tensioactive agents [5]. Things become even more complicated when adding polyelectrolyte to the sludge for ease of the watersolid separation. This mixture can lead to a sludge with a particular rheological behavior due to the interfacial phenomena appearing at the particles interface with water, previously studied in [6].

The present work studies the mixing of the sludge in stirred tanks, a unit operation in a more complex process of sludge recovery in products such as a binder in coke briquettes formulas. The study will conclude in a mathematical model for the prediction of the power consumption at the mixing in vessels equipped with impellers.

\section{Theoretical aspects}

The parameters used to characterize the flow and the mixing in stirred tanks can be calculated by different correlations available in the literature [7- 
12]. In many cases, these parameters can also be computed from the mathematical models.

In all mathematical models, the power number is a dimensionless parameter that provides the measure of power requirements for the impeller mixing operation. It is defined as (Eq. 1) [13]:

$$
N_{p}=\frac{P}{\rho \cdot N^{3} \cdot d^{5}}
$$

where: $P$ is the power consumption in $\mathrm{W}, \rho$ - the density of the fluid in $\mathrm{kg} / \mathrm{m}^{3}, d$ is the impeller diameter in $\mathrm{m}$ and $N$ the impeller speed in rotations per second (rps).

The other main parameter of the mixing process is the Reynolds number. Processing with mechanical mixers occurs either under laminar or under turbulent flow conditions, depending on the Reynolds number, defined as (Eq. 2):

$$
\operatorname{Re}=\frac{\rho \cdot N \cdot d^{2}}{\eta}
$$

where: $\eta$ is the fluid effective viscosity in Pa-s. For Reynolds numbers below 10, the mixing process is considered laminar. Fully turbulent conditions are achieved at Reynolds numbers higher than about $10^{4}$, and the flow is considered transitional between this two limits.

In a previous work [6], the relationship between the shear stress $\tau$ and the shear rate $\gamma$ of sludge was found to be best described by the Herschel-Bulkley non-Newtonian model Eq.(3):

$$
\tau=\tau_{0}+k \dot{\gamma}^{n}
$$

and since effective viscosity,

$$
\eta=\frac{\tau_{0}}{\dot{\gamma}}+k(\dot{\gamma})^{n-1}
$$

where: $\tau_{0}$ is the yield stress, in $\mathrm{Pa}, k$ is the consistency index, in $\mathrm{Pa} \cdot \mathrm{s}^{\mathrm{n}}$ and $n$ is called "the flow behavior index". Therefore, the Reynolds number is written out in its full form as:

$$
\operatorname{Re}=\frac{\rho \cdot N \cdot d^{2}}{\eta}=\frac{\dot{\gamma} \rho N D^{2}}{\tau_{0}+k(\dot{\gamma})^{n}}
$$

The mathematical model of the mixing should correlate with precision the two main parameters of the process: the power number $\mathrm{N}_{\mathrm{p}}$ and the Reynolds number, $R e$.

\section{Experimental}

\subsection{Origin and nature of sludge}

The sludge samples used in this study were collected from wastewater treatment plant in a petrochemical complex, after the final dewatering of sludge. Before the treatment processes, the industrial wastewater is mixed with a municipal wastewater, so the sludge proceeds from both sources.

Table 1. The main properties of sludge

\begin{tabular}{|l|c|l|}
\hline Properties & $\begin{array}{l}\text { ASTM } \\
\text { method }\end{array}$ & Value \\
\hline Density at $25^{\circ} \mathrm{C}, \mathrm{g} / \mathrm{cm}^{3}$ & D1480-02 & 1.0352 \\
\hline $\begin{array}{l}\text { Solid suspension } \\
\text { concentration }(\mathrm{SSC}), \% \\
\text { (w/w) }\end{array}$ & D 482-03 & 33.93 \\
\hline $\begin{array}{l}\text { Water content, } \\
\%(\mathrm{w} / \mathrm{w})\end{array}$ & D 6866 & 66.07 \\
\hline Oil content, $\mathrm{mg} / \mathrm{kg}$ & D 5369-08 & 65852 \\
\hline Ash content, \% $(\mathrm{w} / \mathrm{w})$ & D 482-03 & 27.8 \\
\hline
\end{tabular}

This sludge was collected in the end of the process, after filtration by centrifugation. The main properties of sludge and the corresponding ASTM methods are shown in Table 1.

\subsection{Equipment}

For the sludge samples rheological behavior determination was used a rheoviscometer, RHEOTHEST 2 with coaxial cylinders, consisting in two units: the viscometer and the block with the 
measuring apparatus [14]. The description of apparatus and the rheological study is detailed in [6].

The mixing study was performed in a laboratory agitator vat TLA 30 (Fig. 1) equipped with an anchor impeller with $68 \mathrm{~mm}$ diameter and 8 speed ratio steps from 100 to $800 \mathrm{rpm}$. The cylindrical tank of $80 \mathrm{~mm}$ inner diameter is made of glass with a dished bottom in torispherical shape.

The apparatus is equipped with double wall recipient for heating and a thermometer casing.
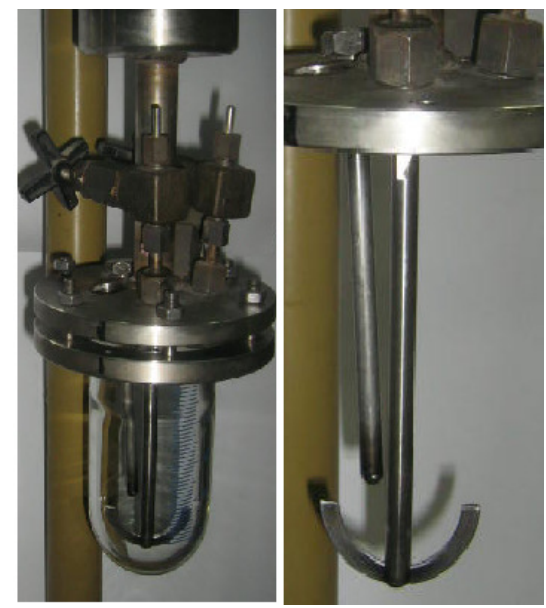

Fig. 1. Mixing equipment

The power consumption $P_{t}$ is measured with a wattmeter connected to the agitator vat. The mixing power $P$ is hence calculated taking into account the power consumption $P_{e}$ in blank operation (empty vessel), with Eq.(6):

$$
P=\left(P_{t}-P_{e}\right) \cdot \frac{N}{N_{\max }} \cdot \frac{\tau}{\tau_{\max }}
$$

Where $N, \tau$ are the rotation speed and the shear stress at that rotation speed, and $N_{\max }, \tau_{\max }$ are the same measures at the maximum speed of the apparatus, $13.3 \mathrm{rps}$.

\subsection{Experimental data acquisition}

The mixing was conducted at four different $H / d$ ratios , $H$ being the level of the fluid in the tank and $d$, its inner diameter. For each $H / d$ ratio $\left(H_{1}=0.15 m\right.$, $H_{2}=0.12 \mathrm{~m}, H_{3}=0.09 \mathrm{~m}$ and $H_{4}=0.06 \mathrm{~m}$ ), the mixing was performed at eight different rotation speeds. The power consumption was measured in each case. So, there were 32 sets of data. The power consumption was measured in each case.

For the correlation $N_{p}-R e$, the values of the effective viscosity were needed and these values depend on the rotation speed. There were used the rheological data from [6] (see Fig.2) and hence the effective viscosity was calculated at the given rotation speeds.

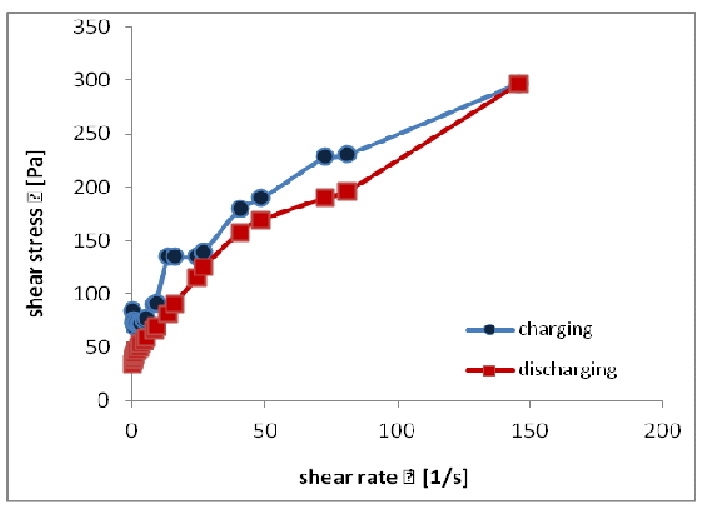

Fig. 2. Rheogram for sludge sample at $25^{\circ} \mathrm{C}$ [6]

The equation which describe the variation of shear stress versus shear rate for the sludge sample (ascending curve) is Herschel-Bulkley model (Eq.3), where the value of the coefficients are: $\tau_{0}=$ $80.051 \mathrm{~Pa}, k=7.688 \mathrm{~Pa} \cdot \mathrm{s}^{n}, n=0.637$ and the correlation coefficient is $R^{2}=0.948$.

Accordingly, the effective viscosity of the fluid at a given rotation speed was calculated with Eq.(7):

$$
\eta=\frac{\tau_{0}}{\gamma}+k(\dot{\gamma})^{n-1}
$$




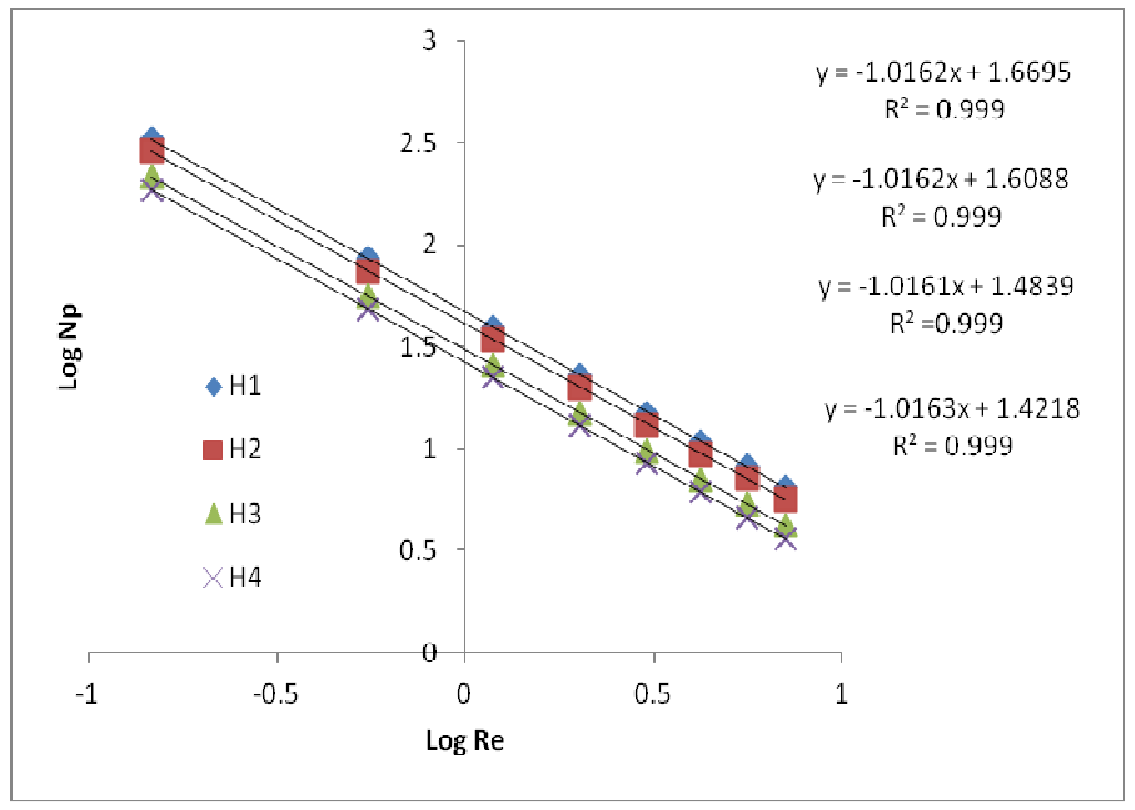

Fig. 3. Power curves at different levels $\left(H_{1}=0.15 \mathrm{~m}, H_{2}=0.12 \mathrm{~m}, H_{3}=0.09 \mathrm{~m}\right.$ and $\left.H_{4}=0.06 \mathrm{~m}\right)$ of sludge in the vessel

\section{Results and discussions}

From the values of $N_{p}$ and $R e$ the variation curves $N_{p}$ versus $R e$ were drawn, as seen in Fig. 3 plotted in logarithmic scale.

The equations describing the variation $N_{p}=f(\mathrm{Re})$ and the correlation coefficient $R^{2}$ are presented in Table 2 .

Table 2. The variation $N_{p}=f(\mathrm{Re})$ and the correlation coefficients $R^{2}$ for different $H / d$ ratio

\begin{tabular}{|c|c|c|}
\hline $\begin{array}{c}H / \boldsymbol{d} \\
\text { ratio }\end{array}$ & $\begin{array}{c}N_{p}=f(\mathrm{Re}) \\
\text { curve equation }\end{array}$ & $\boldsymbol{R}^{2}$ \\
\hline 2.206 & $N_{p}=1.669 \mathrm{Re}^{-1.016}$ & 0.999 \\
\hline 1.765 & $N_{p}=1.609 \mathrm{Re}^{-1.016}$ & 0.999 \\
\hline 1.323 & $N_{p}=1.484 \mathrm{Re}^{-1.016}$ & 0.999 \\
\hline 0.882 & $N_{p}=1.422 \mathrm{Re}^{-1.016}$ & 0.999 \\
\hline
\end{tabular}

The parameters of these equations and the correlation coefficient $R^{2}$ were obtained by curve fitting in Excel.

It can be seen from the Table 2 that equations describe power function type: $N_{p}=a \cdot \operatorname{Re}^{b}$ where the coefficient of the model $a$ vary with $H / d$ ratio.By further curve fitting, the proposed mathematical model for the variation $N_{p}=f(\mathrm{Re})$ at different levels of sludge in the vessel is Eq. 8:

$$
N_{p}=(16.114 \cdot H / d+11.176) \cdot \operatorname{Re}^{-1.016}
$$

The trend in the power number correlation is similar to that reported by Pakzad L. et al., [11]. Theory and the experimental studies [11,12] show that $N_{p}$ is proportional with $R e^{-1}$ in the laminar regime and in our study we found that $N_{p}$ is proportional with $R e^{-1.016}$ in this specific case. 


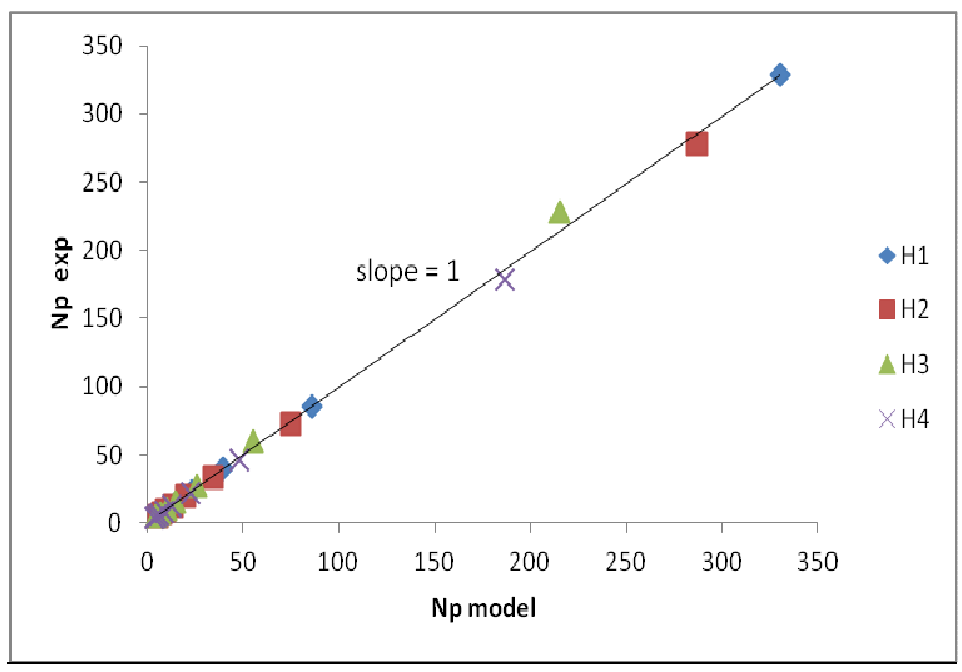

Fig. 4. Experimental power number $\left(N_{p}\right.$ exp $) v s$. computed power number $\left(N_{p}\right.$ model $)$

Figure 4 shows that the laminar flow model developed in this study can be used to predict the mixing behavior of sludge at $R e<10$ because the line with slope of 1 indicates that experimental data fits very well to the computed data.

\section{Conclusions}

The sludge proceeding from industrial and municipal wastewater treatment has a nonNewtonian behavior described by the Herschel Bulkley model.

Due to this particular rheology of the sludge, it resulted that the mixing mathematical model describing the process is a power function: $N_{p}=a \cdot \operatorname{Re}^{b}$.

The coefficient $a$ can be written as a linear function of $\mathrm{H} / \mathrm{d}$ ratio and $b=-1.016$ is a constant value.

The mathematical model is in accordance with the experimental observations: the power consumption increases with the increase of sludge level in the mixing vessel. It was noticed that there was a good agreement between experimental and computed data in the laminar regime up to $R e=10$.
The mathematical model can serve to the dimensioning of industrial vessels with agitation for the particular application of sludge mixing.

\section{References}

*E-mail address: asterpu@ univ-ovidius.ro

[1]. I. Seyssiecq, B. Marrot, D. Djeroud and N. Roche, Chemical Engineering Journal, 142, 4047, (2008)

[2]. M. Mori, I. Seyssiecq and N. Roche, Process Biochemistry, 41, 1656-1662, (2006)

[3]. I. Seyssiecq, J.H. Ferrasse and N. Roche, Biochemical Engineering Journal, 16, 41-56 (2003)

[4]. M .Grigore, C. Koncsag and C. Ioan, European Meeting on Chemical Industry and Environment V, May $3^{\text {rd }}-5^{\text {th }}$, Viena, Austria, 2006, pp. 251-256

[5]. O. Francioso, M.T. Rodriguez-Estrada, D. Montecchio, C. Salomoni, A. Caputo and D. Palenzona, Journal of Hazardous Materials, 175,. 740-746, (2010) 
[6]. A.E. Sterpu, D.I. Arsenie, N. Teodorescu, A.I. Dumitru and A.A. Neagu, Ovidius University Annals of Chemistry, 22, 41-47, (2011)

[7]. D. Anne-Archard, M. Marouche and H.C. Boisson, Chemical Engineering Journal, 125, 15-24, (2006)

[8]. D. Caşcaval, A.-I. Galaction and Ş. Cămăruţ, Environmental Engineering and Management Journal, 8, 17-27, (2009)

[9]. A.-I. Galaction, Ş. Cămăruţ, D. Caşcaval and R. Z. Tudose, Environmental Engineering and Management Journal, 7, 199-211, (2008)

[10]. J.F. Maingonnat, L. Muller and J.C. Leuliet, Journal of Food Engineering, 71, 265-272, (2005)
[11]. L. Pakzad, F. Ein-Mozaffari and Ph. Chan, Chemical Engineering and Processing, 47, 2218-2227, (2008)

[12]. L. Rudolph, M. Schäfer, V. Atiemo-Obeng and M. Kraume, Chemical Engineering Research and Design, 85, 568-575, (2007)

[13]. L.E. Paul, V.A. Atiemo-Obeng and S.M. Kresta, Handbook of industrial mixing. Science and Practice, John Wiley \& Sons, New Jersey, 2004

[14]. N. Teodorescu, Applied rheology, (in Romanian), Matrix Rom Press, Bucharest, 2003, pp. 28-40.

Submitted: November $4^{\text {th }} 2013$ Accepted in revised form:November $12^{\text {th }} 2013$ 